\title{
Vorwort zur fünften Auflage.
}

Die neue Form, in welcher das Buch bei der vierten Auflage erschien, hat eine Änderung in der jetzigen Auflage nicht zu erfahren brauchen. Dank des weitgehendsten Interesses der Kältemaschinen-Industrie, für welches hier ausdrücklich gedankt wird, konnten aber eine größere Zahl neuerer Ausführungsformen im Bild gezeigt werden, wogegen die Bilder einiger inzwischen verlassener Formen ausgeschaltet wurden. Einige auch heute noch gültige Figuren mußten herausgenommen werden, um ohne Vergrößerung des Umfanges des Buches Platz für interessante neue Bilder zu schaffen.

Im Text haben die Ergebnisse einiger neuerer Forschungen, des Kältekongresses in Wien sowie der Jahresversammlungen der deutschen Kälte-Ingenieure Berücksichtigung gefunden. Bei der Durchsicht der Korrektur wurden wir durch Herrn Dipl.-Ing. K. Lapp in Danzig-Langfuhr wirksam unterstützt.

Danzig und Bresla u, November 1912.
H. Lorenz.
C. Heinel. 
